\title{
Potential Source of Medicinal Compounds from Liverworts: Bibenzyls and Bis(bibenzyls)
}

\author{
Yoshinori Asakawa*
}

Fakulty of Pharmaceutical Sciences, Tokushima Bunri University, Yamashiro-cho, Tokushima 770-8514; E-mail: asakawa@ph.bunri-u.ac.jp

Liverworts produce a number of new skeletal terpenoids and aromatic compounds of which bibenzyls and bis(bibenzyls) are characteristic chemical markers of liverworts. Some of these compounds, riccardin A (1), riccardin C (2), marchantins A (3), B (4), C (5), E (6), H (7), isoplagiochin A (8), isoplagiochin B, (9) perrottetin F (10), isoplagiochin C (11), and bis(bibenzyl) dimers, pusilatins A-D (12-15) and show various biological activity such as anti-microbial, anti-fungal, antioxidant, antiinfluenza, anti-obesity, anti-HIV, muscle relaxing, cytotoxicity, plant grow regulatory, liver Z-receptor agonist activity, and nitric oxide production, DNA polymerase, $\alpha$-glucosidase and tublin polymerization inhibitory activity.

The present paper concerns with the isolation, structure elucidation and biological activity of bibenzyls and bis(bibenzyls) found in the Marchanita, Reboulia, Plagiochila and Plagiochasma species.

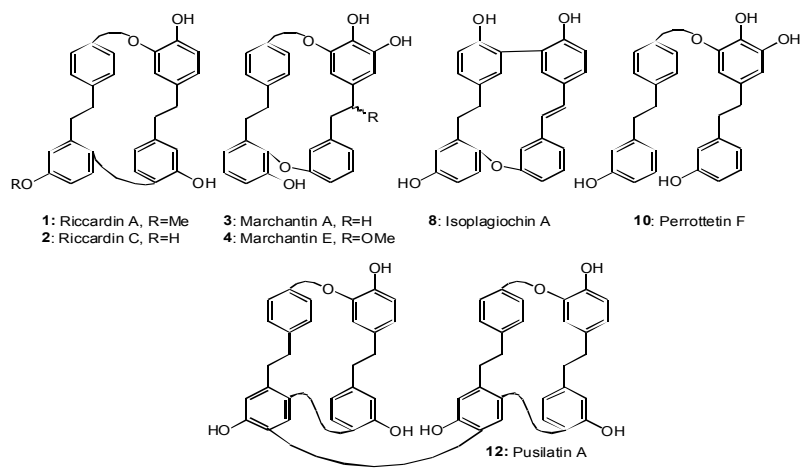

Keywords: Liverworts, bibenzyls, bis(bibenzyls), antiinfluenza, antimicrobial, tublin polymerization inhibitory. 